\title{
JULIO DE 1977
}

2do AÑo - Núm. 19

\section{revista internacional de la cruz roja}

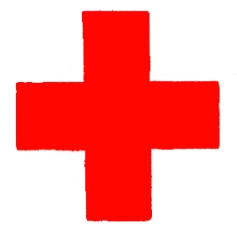

INTER ARMA CARITAS

GINEBRA

COMITÉ INTERNACIONAL DE LA CRUZ ROJA FUNDADO EN 1863 


\section{COMITÉ INTERNACIONAL DE LA CRUZ ROJA}

Sr. ALEXANDRE HAY, abogado, ex director general del Banco Nacional Suizo, presidente (miembro desde 1975)

Sr. JEAN PICTET, doctor en derecho, presidente de la Comisión Juridica, director del Instituto Henry Dunant, profesor asociado de la Universidad de Ginebra, vicepresidente (1967)

Sr. HARALD HUBER, doctor en derecho, juez federal, vicepresidente (1969)

Sra. DENISE BINDSCHEDLER-ROBERT, doctora en derecho, profesora del Instituto Universitario de Altos Estudios Internacionales de Ginebra, juez en el Tribunal Europeo de Derechos del Hombre (1967)

Sr. MARCEL A. NAVILLE, licenciado en letras, ex presidente del CICR (de 1969 a 1973)

Sr. JACQUES F. DE ROUGEMONT, doctor en medicina (1967)

Sr. ROGER GALLOPIN, doctor en derecho, ex director general del CICR, ex presidente del Consejo Ejecutivo (1967)

Sr. VICTOR H. UMBRICHT, doctor en derecho, administrador (1970)

Sr. GILBERT ÉTIENNE, profesor del Instituto Universitario de Altos Estudios Internacionales y del Instituto de Estudios de Desarrollo, Ginebra (1973)

Sr. ULRICH MIDDENDORP, doctor en medicina, jefe de la clínica quirúrgica del Hospital cantonal, Winterthur (1973)

Sra. MARION BOVEE-ROTHENBACH, diplomada M.S.W. de la Universidad de Michigan, profesora asistente de la Escuela de Ciencias Sociales y Políticas de la Universidad, Lausana (1973)

Sr. HANS PETER TSCHUUDI, doctor en derecho, ex consejero federal (1973)

Sr. HENRY HUGUENIN, director de banco (1974)

Sr. GOTTFRIED DE SMIT, administrador (1974)

Sr. JAKOB BURCKHARDT, doctor en derecho, ministro plenipotenciario, presidente del Consejo de las Escuelas Politécnicas Federales (1975)

Sr. THOMAS FLEINER, doctor en derecho, profesor de la Universidad de Friburgo (1975)

Sr. HERBERT LUTHY, doctor en filosofia, profesor de historia en la Universidad de Basilea (1975)

Sr. RICHARD PESTALOZZI, doctor en derecho, asistente especial del presidente (1977)

Miembros honorarios: Sria. LUCIE ODIER, vicepresidenta honoraria; Sres. HANS BACHMANN, GUILLAUME BORDIER, Sra. MARGUERITE GAUTIER-VAN BERCHEM, Sres. ADOLPHE GRAEDEL, EDOUARD DE HALLER, ERIC MARTIN, RODOLFO OLGIATI, MAX PETITPIERRE, PAUL RUEGGER, DIETRICH SCHINDLER, FREDERIC SIORDET, ALFREDO VANNOTTI.

\section{CONSEJO EJECUTIVO}

Sr. ALEXANDRE HAY, presidente

Sr. VICTOR H. UMBRICHT, vicepresidente

Sr. RICHARD PESTALOZZI

STa. DENISE BINDSCHEDLER-ROBERT

Sr. THOMAS FLEINER

Sr. JEAN PICTET 


\section{REVISTA INTERNACIONAL DE LA CRUZ ROJA}

\section{ÍNDICE}

JULIO DE 1977 - Núm. 19

COMITÉ INTERNACIONAL DE LA CRUZ ROJA

EN EL MUNDO

DE LA CRUZ ROJA
Conferencia Diplomática - Resumen de los trabajos del cuarto período de sesiones . . . . . 341

Viajes del presidente del CICR . . . . . . . . 379

Visita de la presidenta de la Media Luna Roja Marroquí .. . . . . . . . . . . . 379

Visita del príncipe Hassan de Jordania . . . . 380 Adhesión a los Convenios de Ginebra . . . . . 380

Exposición de la Media Luna Roja Marroquí en el Museo de Castiglione . . . . . . . . . 384

Alta distinción de la Cruz Roja Neerlandesa al director del Servicio Internacional de Búsquedas 385

Séptimo Festival internacional de películas de la Cruz Roja y sobre la salud en Varna . . . 386 Difusión de los Convenios de Ginebra . . . . 388

Lista de los Estados Partes en los Convenios de Ginebra del 12 de Agosto de 1949 . . . . . . . 394 
REVUE INTERNATIONALE DE LA CROIX-ROUGE

\section{INTERNATIONAL}

REVIEW

OF THE RED CROSS

ARTICULOS Y PASAJES

DE LA REVISTA

EN LeNGUa aLemANA
Aparecen mensualmente ediciones en lenguas inglesa $y$ francesa que pueden obtenerse en las mismas condiciones.

Charles Zorgbibe: Die Anerkennung des Kriegszustandes - Ein Überblick II - HBC 88 - Das Funknetz des IKRK - IKRK Mitglied demissioniert.

REVISTA INTERNACIONAL DE LA CRUZ ROJA
Publicada mensualmente por el Comité Internacional de la Cruz Roja.

17, avenue de la Paix, 1211 Ginebra (Suiza) - Número de cuenta postal 12-1767.

Subscripción anual : 30.- Fr.; cada número: 3.- Fr.

REDACción: Michel TESTUZ

El Comité Internacional de la Cruz Roja sólo se responsabiliza de los textos publicados con su firma. 